\title{
Deletion of Apolipoprotein E Receptor-2 in Mice Lowers Brain Selenium and Causes Severe Neurological Dysfunction and Death When a Low-Selenium Diet Is Fed
}

\author{
Raymond F. Burk, ${ }^{1}$ Kristina E. Hill, ${ }^{1}$ Gary E. Olson, ${ }^{2}$ Edwin J. Weeber, ${ }^{3}$ Amy K. Motley, ${ }^{1}$ Virginia P. Winfrey, ${ }^{2}$ and \\ Lori M. Austin ${ }^{1}$ \\ ${ }^{1}$ Division of Gastroenterology, Hepatology, and Nutrition, Department of Medicine, ${ }^{2}$ Department of Cell and Developmental Biology, and ${ }^{3}$ Department of \\ Molecular Physiology and Biophysics, Vanderbilt University School of Medicine, Nashville, Tennessee 37232
}

\begin{abstract}
Selenoprotein P (Sepp1) is a plasma and extracellular protein that is rich in selenium. Deletion of Sepp1 results in sharp decreases of selenium levels in the brain and testis with dysfunction of those organs. Deletion of Sepp1 also causes increased urinary selenium excretion, leading to moderate depletion of whole-body selenium. The lipoprotein receptor apolipoprotein E receptor-2 (apoER2) binds Sepp 1 and facilitates its uptake by Sertoli cells, thus providing selenium for spermatogenesis. Experiments were performed to assess the effect of apoER2 on the concentration and function of selenium in the brain and on whole-body selenium. ApoER2 $2^{-/-}$and apoER2 $2^{+/+}$ male mice were fed a semipurified diet with selenite added as the source of selenium. ApoER2 ${ }^{-1-}$ mice had depressed brain and testis selenium, but normal levels in liver, kidney, muscle, and the whole body. Feeding a selenium-deficient diet to apoER2 ${ }^{-/-}$mice led to neurological dysfunction and death, with some of the characteristics exhibited by Sepp $1^{-/-}$mice fed the same diet. Thus, although it does not affect whole-body selenium, apoER2 is necessary for maintenance of brain selenium and for prevention of neurological dysfunction and death under conditions of selenium deficiency, suggesting an interaction of apoER2 with Sepp1 in the brain.
\end{abstract}

Key words: brain selenium deficiency; neurological dysfunction; apoER2 knock-out; selenoprotein P; low selenium intake; normal wholebody selenium

\section{Introduction}

Selenoprotein P (Sepp1) is a selenium-rich extracellular protein that is expressed by nearly all tissues, but is produced in largest quantities by the liver (Burk and Hill, 2005). Approximately 75\% of the selenium in mouse plasma is in Sepp1 (Hill et al., 2007) and this protein has been postulated to transport the element from the liver to other tissues.

Sepp1 null $\left(S e p p 1^{-/-}\right)$mice have several phenotypes. They have very low selenium concentration in brain $(<50 \%$ of Sepp $1^{+/+}$) and testis ( $<20 \%$ of Sepp $1^{+/+}$) (Hill et al., 2003). Also, their whole-body selenium concentration is $75 \%$ or less that of Sepp $1^{+/+}$mice (Burk et al., 2006; Hill et al., 2007). Urinary wasting of selenium occurs in Sepp1 $1^{-/-}$mice and was concluded to be the cause of their low whole-body selenium.

The low brain selenium level in $\operatorname{Sepp1^{-/-}}$ mice has clinical consequences. Feeding weanling $\operatorname{Sepp} 1^{-1-}$ mice a seleniumdeficient diet resulted in neurological dysfunction and death within several weeks (Hill et al., 2003, 2004). Feeding them a high-selenium diet prevented all but minor neurological deficits.

Received March 14, 2007; revised April 30, 2007; accepted May 5, 2007.

This work was supported by National Institutes of Health Grants ES02497, HD44863, and ES00267.

Correspondence should be addressed to Raymond F. Burk, $1030 \mathrm{C}$ Medical Research Building IV, Vanderbilt Medical Center, Nashville, TN 37232-0252. E-mail: raymond.burk@vanderbilt.edu.

DOI:10.1523/JNEUROSCI.1153-07.2007

Copyright $\odot 2007$ Society for Neuroscience $\quad$ 0270-6474/07/276207-05\$15.00/0
The low testis selenium level was associated with production of abnormal spermatozoa, which appeared to be identical to spermatozoa produced by selenium-deficient mice (Olson et al., 2005). Sepp $1^{-/-}$males had very low fertility.

In the course of experiments aimed at determining the mechanism by which Sepp1 provided selenium to the testis, Olson et al. (2007) identified the apolipoprotein E receptor-2 (apoER2), also known as LRP8, as responsible for uptake of Sepp1 by Sertoli cells of the seminiferous tubule. They concluded that the Sepp1apoER2 interaction supplies the selenium used for spermatogenesis. ApoER2, a member of the low-density lipoprotein receptor family, is expressed predominantly in the brain and testis (Kim et al., 1996). Until our recent discovery that it facilitates the uptake of Sepp1, no ligand of testicular apoER2 had been identified.

Brain apoER2 has been characterized primarily as a signaling receptor. In addition to apoE, the extracellular protein Reelin is also a ligand of apoER2 (Herz and Bock, 2002). Reelin signaling through apoER2 and the very low-density lipoprotein receptor is involved in neuronal migration during brain development and plays a role in learning and memory during adult life (Weeber et al., 2002; Beffert et al., 2005, 2006a) Also, a previous report demonstrated that the absence of apoER2 accelerates loss of corticospinal neurons in adult mice (Beffert et al., 2006b). Thus, the receptor appears to be necessary for neuron survival.

In the work reported here, we studied mice with deletion of 
apoER2 to assess the degree to which they would manifest the extratesticular phenotypes of Sepp1 deletion. The neurological phenotype of Sepp 1 deletion has similarities to that of deletion of apoER2, but the deletion does not affect whole-body selenium concentration.

\section{Materials and Methods}

Reagents. NADPH was purchased from USB (Cleveland, OH). Glutathione and glutathione reductase were purchased from Sigma (St. Louis, MO). ${ }^{75}$ Se-selenite (specific activity, $\sim 1100 \mathrm{Ci} / \mathrm{g}$ ) was purchased from the University of Missouri Research Reactor Facility (Columbia, MO). Other chemicals used were of reagent grade.

Animals. Sepp $1^{-1-}$ and Sepp $1^{+1+}$ male mice congenic with the strain C57BL/ 6 were produced by breeding as described previously (Hill et al., 2003, 2007). ApoER2 $2^{-/-}$mice (strain name, B6;129S6-Lrp8 $\left.8^{\text {tm } 1 \mathrm{Her} / J}\right)$ were purchased from The Jackson Laboratory (Bar Harbor, ME). Male pups from heterozygote matings were genotyped by PCR according to the Lrp $8{ }^{\text {tm1Her }}$, version 1, protocol obtained from The Jackson Laboratory. At weaning, apoER2 $2^{-/-}$and apoER2 $2^{+/+}$pups were fed a torula yeast diet (Hill et al., 2004) supplemented with 0 or $0.25 \mathrm{mg}$ of selenium in the form of sodium selenite per kilogram of diet. The diet was formulated and pelleted to our specifications by Harlan-Teklad (Madison, WI). Mice were provided food and water ad libitum. They were housed on aspen shavings in a room with a 10/14 h light/dark cycle in an Association for Assessment and Accreditation of Laboratory Animal Care Internationalapproved facility. The Vanderbilt University Institutional Animal Care and Use Committee approved all experiments.

Biochemical assays. Mice were anesthetized with isoflurane and exsanguinated by withdrawing blood from the inferior vena cava using a syringe and needle. The blood was treated with disodium EDTA $(1 \mathrm{mg} / \mathrm{ml})$ to prevent coagulation and plasma was separated by centrifugation. Tissues were removed and frozen immediately in liquid nitrogen. They were stored at $-20^{\circ} \mathrm{C}$ until assayed for selenium.

Sepp1 concentration was determined by ELISA (Hill et al., 2007). Plasma glutathione peroxidase activity was measured using $0.25 \mathrm{~mm}$ $\mathrm{H}_{2} \mathrm{O}_{2}$ as substrate (Lawrence and Burk, 1976). One unit of activity represents $1 \mathrm{nmol}$ of NADPH oxidized per min. Selenium was measured as before (Burk et al., 2006) using a modification of the fluorometric assay of Koh and Benson (Koh and Benson, 1983; Sheehan and Gao, 1990). The detection limit of this assay is $1 \mathrm{ng}$ of selenium.

${ }^{75} \mathrm{Se}$ and selenium urinary excretion studies. ApoER $2^{-1-}$ and apoER $2^{+/+}$mice were administered ${ }^{75} \mathrm{Se}$-selenite $(10 \mu \mathrm{Ci})$ by gavage in $0.25 \mathrm{ml}$ of $0.15 \mathrm{M} \mathrm{NaCl}$ after fasting overnight. After ${ }^{75} \mathrm{Se}$ administration, mice were housed individually in metabolic cages for $24 \mathrm{~h}$. Urine was collected after $24 \mathrm{~h}$ and ${ }^{75} \mathrm{Se}$ radioactivity and selenium content were measured. ${ }^{75}$ Se was determined using a Perkin-Elmer (Shelton, CT) 1480 Wizard 3" Gamma Counter.

Survival of mice fed a selenium-deficient diet. At weaning, apoER2 $2^{-1-}$ mice were fed the torula yeast diet without supplemental selenium. The mice were observed daily (except on weekends). Mice were weighed weekly and, after observation of clinical signs of neurological dysfunction, at least every other day. Weight loss of $20 \%$ of the highest recorded body weight triggered euthanasia, regardless of neurological status.

\section{Results}

Tissue and whole-body selenium levels in apoER2 $2^{-/-}$mice Tissue selenium concentrations were determined in apoER2 $2^{-1-}$ and $a p o E R 2^{+/+}$mice fed a nutritionally adequate level of selenium (Fig. 1). Two of the tissues studied were affected by deletion of apoER2: brain and testis selenium were 44 and 27\% of the respective values in apoER2 $2^{+/+}$mice. Muscle, kidney, and liver selenium concentrations were not significantly affected. Thus, the effect of apoER2 on selenium levels in the tissues studied was restricted to the brain and testis.

Deletion of apoER2 did not affect whole-body selenium concentration (Fig. 1) or urinary excretion of selenium (Table 1). This contrasts with the elevated urinary excretion of ingested

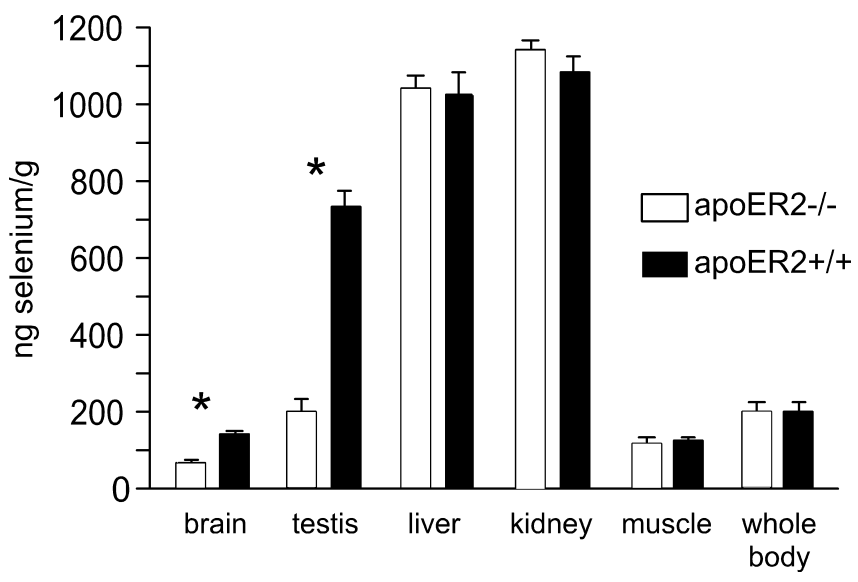

Figure 1. Effect of deletion of apoER2 on tissue selenium concentration in mice. The mice were fed a diet supplemented with $0.25 \mathrm{mg}$ of selenium $/ \mathrm{kg}$ diet for 4 weeks beginning at weaning. The mouse selenium nutritional requirement is $0.1 \mathrm{mg} / \mathrm{kg}$ diet. Whole-body selenium was calculated for each mouse by summing the values of each tissue and the residual carcass. Values shown are means and error bars representing 1 SD $(n=5)$. Asterisks indicate the tissues that were different $(p<0.05)$ by Student's $t$ test between genotypes.

Table 1. Urinary ${ }^{75} \mathrm{Se}$ and total selenium excretion by mice with apoER2 deleted

\begin{tabular}{lcc}
\hline Form of 'selenium & $a p o E R^{-/-}$ & $a p o E R 2^{+/+}$ \\
\hline & $n=6$ & $n=4$ \\
${ }^{75}$ Se (\% gavaged dose/24 h) & $16 \pm 4.8$ & $15 \pm 3.4$ \\
Selenium (ng/24 h) & $270 \pm 160$ & $240 \pm 100$ \\
\hline
\end{tabular}

Mice were fed a diet containing $0.25 \mathrm{mg}$ selenium $/ \mathrm{kg}$ diet for $4-5$ weeks beginning at weaning. Values are means $\pm S D$ of the percentage of ${ }^{75}$ Se gavaged and selenium content of urine. Neither determination was different by Student's $t$ test between genotypes.

Table 2. Plasma selenoproteins and selenium in mice with deletion of apoER2

\begin{tabular}{|c|c|c|c|}
\hline & $\begin{array}{l}\text { apoER2 } \\
\text { mice }^{a}\end{array}$ & $\begin{array}{l}\text { apoER2 } 2^{+/+} \\
\text {mice }^{a}\end{array}$ & $\begin{array}{l}\text { apoER2 } 2^{-1-} / \\
\text { apoER2 }\end{array}$ \\
\hline & $n=5$ & $n=5$ & \\
\hline Glutathione peroxidase (U/L) & $490 \pm 36$ & $450 \pm 51$ & 1.09 \\
\hline Selenoprotein P (mg/L) & $37 \pm 6^{b}$ & $29 \pm 4^{b}$ & 1.24 \\
\hline Selenium ( $\mu \mathrm{g} / \mathrm{L})$ & $450 \pm 52^{c}$ & $370 \pm 45^{c}$ & 1.25 \\
\hline
\end{tabular}

Mice were fed a diet containing $0.25 \mathrm{mg}$ selenium $/ \mathrm{kg}$ diet for $4-5$ weeks beginning at weaning.

${ }^{a}$ Values are means $\pm S D$.

$b, c$ Pairs of values significantly different from one another by Student's t test $(p<0.05)$ have the same superscript

selenium and the decrease in whole-body selenium observed in mice with deletion of Sepp1 (Burk et al., 2006).

Plasma selenium biomarkers in apoER2 $2^{-1-}$ mice

Plasma Sepp1 concentration was increased in mice with deletion of apoER2 (Table 2). Plasma glutathione peroxidase activity was not affected. The Sepp1 increase was reflected by an increase in plasma selenium concentration. Whether the cause of the Sepp1 increase was the absence of apoER2-facilitated removal of it from plasma cannot be ascertained from the present results.

\section{Neurological function in $a p o E R 2^{-/-}$mice}

Because neurological dysfunction had occurred in Sepp1 ${ }^{-/-}$mice when they were fed a selenium-deficient diet, 15 weanling male apoER2 $2^{-1-}$ mice were fed a selenium-deficient diet and observed for neurological signs. The predominant early neurological sign in those apoER2 $2^{-I-}$ mice was a pronounced startle response to 


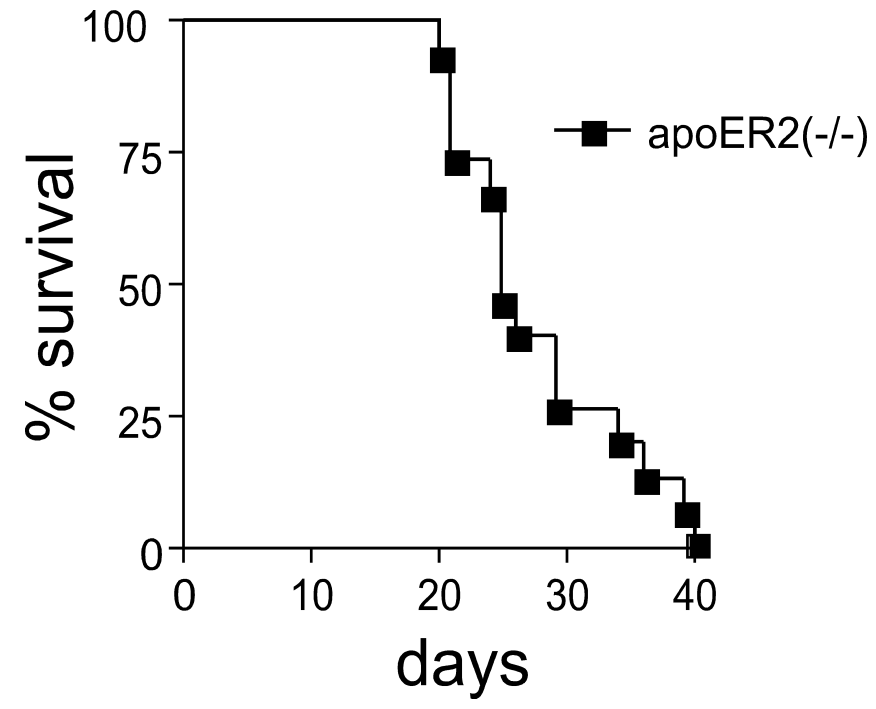

Figure 2. Survival of apoER2 ${ }^{-1-}$ male mice $(n=15)$ fed a selenium-deficient diet beginning at weaning. Wild-type $\left(a p o E R 2^{+/+}\right)$mice do not develop neurological dysfunction when fed a selenium-deficient diet and do not have shortened survival.

hand clap or other stimulation. Three of the mice jumped four or more inches above the table surface in response to a clap and continued to jump with subsequent claps. Thirteen of the mice exhibited hyperactive behavior when stimulated between days 19 and 35 , running in their cages and bumping into the sides. Of these 13 , four also exhibited retropulsion and three lost $20 \%$ or more of their body weight. One mouse exhibited retropulsion as the only neurological sign and one mouse died without having been observed to have neurological signs. All mice died (or were killed) usually within $3 \mathrm{~d}$ of developing signs. Fifty percent of the mice had died by day 25 and all had died by day 40 (Fig. 2). ApoER $2^{+/+}$mice fed a selenium-deficient diet had a normal appearance and did not exhibit these behaviors (data not shown).

\section{Discussion}

This study demonstrates that apoER2 is necessary for maintenance of brain selenium and for preservation of neurological function and survival under conditions of selenium deficiency. Thus, apoER2 plays an important role in the metabolism and function of selenium in the brain.

Selenium is present in biological systems as selenoproteins, which characteristically are oxidoreductases. These selenoenzymes have a variety of activities (Kryukov et al., 2003) and many of them, including the glutathione peroxidases and the thioredoxin reductases, have oxidant defense functions. Under conditions of selenium deficiency, tissue levels of these enzymes fall and oxidative stress conditions develop (Yang et al., 1989; Burk, 2006). This increases the susceptibility of cells to certain types of oxidative damage and death (Burk and Lane, 1983; Burk et al., 1995). Therefore, maintenance of the brain selenium level, a reflection of selenoprotein content, is important to brain cell function and survival.

The brain maintains its selenium better than any other organ or tissue during selenium deficiency (Nakayama et al., 2007). The severe neurological consequences of selenium loss when either Sepp1 or apoER2 is deleted demonstrates the brain's great need for selenium and provides a rationale for its having developed a mechanism to maintain selenium at the expense of other tissues.

Selenium levels in the brain and testis are dependent on the presence of apoER2 (Fig. 1). However, preliminary immunocytochemistry studies have not identified apoER2-dependent Sepp1-containing vesicles in the brain (G. E. Olson and V. P. Winfrey, unpublished observations), as were observed in the testis (Olson et al., 2007). Differences between uptake mechanisms in the brain and testis were demonstrated in rats over 15 years ago (Burk et al., 1991). Intravenous administration of ${ }^{75} \mathrm{SE}-$ labeled Sepp1 was associated with greater brain, but not testis, ${ }^{75} \mathrm{SE}$ accumulation in selenium-deficient rats than in selenium-replete rats. A difference was already present 5 min after administration, strongly suggesting the presence at the blood-brain barrier of a mechanism of selenium uptake directly from Sepp 1. Moreover, it suggests that the uptake mechanism was induced under conditions of selenium deficiency.

Although there is controversy over which cells express apoER2 in the brain, it is generally agreed that the receptor is present on neurons (D'Arcangelo et al., 1999; Trommsdorff et al., 1999) and on some glial cells that are neuron precursors (Hartfuss et al., 2003; Thilakawardhana et al., 2005). There is little evidence that apoER2 is present at the blood-brain barrier. Therefore, the nature of selenium uptake from Sepp1 at the blood-brain barrier remains unknown. Possibilities include uptake mediated by a receptor other than apoER2, uptake mediated by the heparin-binding properties of Sepp1 (Hondal et al., 2001), and uptake of a selenium-containing fragment of Sepp1 (Ma et al., 2003). The last alternative would likely involve binding of Sepp1 at the blood-brain barrier and removal of selenium or a selenium-containing fragment from it for transport across the blood-brain barrier. Precedent for such a mechanism is provided by the recent demonstration that a transmembrane protein, STRA6, binds the retinol-binding protein-vitamin A complex and facilitates the transfer of vitamin A into the cell without using endocytosis (Kawaguchi et al., 2007).

Both apoER2 and Sepp1 are expressed within the brain (Saijoh et al., 1995). Therefore, it is likely that Sepp1 transports selenium from brain cells that synthesize it (e.g., astrocytes) (Yang et al., 2000), to cells that express apoER2 (e.g., neurons). Such a selenium economy inside the blood-brain barrier might contribute to the ability of the brain to conserve its selenium (Schweizer et al., 2005).

Effects of apoER2 and of Sepp1 on the brain have been studied using mice with deletion of each protein. Table 3 lists some effects of deleting each protein, allowing comparison of them. Both deletions cause severe depression of brain selenium. Moreover, they both transform dietary selenium deficiency into a lethal condition with severe neurological dysfunction. Thus, both deletions impact brain selenium metabolism severely and have similar outcomes under conditions of selenium deficiency.

Not all of the abnormalities associated with deletion of apoER 2 are mimicked by deletion of Sepp1. For example, proper migration of certain neurons during brain development depends on the presence of apoER2 but not on the presence of Sepp1 (Table 3). Similarly, associative learning defects are present in mice with deletion of apoER2, but not in those with deletion of Sepp1. Long-term potentiation in the hippocampus is impaired to a greater extent when Sepp1 is lost than when apoER2 is lost. Signaling by apoER 2 has been postulated to underlie its actions in the brain. The present observations that apoER2 has profound effects on selenium in the brain and that some of the effects of apoER2 deletion are found when Sepp1 is deleted must now be considered alongside signaling in assessing the mechanisms by which this receptor functions.

It has been postulated that apoER2 plays a role in the devel- 
opment of Alzheimer's disease (Beffert et al., 2006b). The E4 allele of the apoER2 ligand apoE is strongly linked to development of the disease (Weisgraber and Mahley, 1996). If our postulate is correct that apoER2 interacts with Sepp1 in the brain to maintain brain selenium content, an effect of apoE4 on this interaction might play a role in the pathogenesis of Alzheimer's disease.

With the exception of an increase in plasma Sepp1, the effects of apoER2 on selenium appear to be limited to the brain and the testis (Fig. 1). The apoER2 ligand Sepp1 has at least one more effect, however, the regulation of whole-body selenium (Burk et al., 2006). The effect on whole-body selenium originates in the liver where Sepp 1 synthesis competes with synthesis of urinary excretory metabolites. In the absence of Sepp1, there is increased urinary selenium excretion that leads to decreased whole-body selenium. ApoER2 is not involved in that Sepp1 effect (Fig. 1, Table 1).

In summary, mice with deletion of apoER2 have low brain selenium and develop neurological dysfunction and die when fed selenium-deficient diet, much as do mice with deletion of the apoER2 ligand Sepp1. The testis depends on apoER2-mediated endocytosis of Sepp1 to maintain its selenium, but brain selenium uptake and conservation appears to be more complex and has not yet been fully elucidated. The link of selenium and Sepp1 with apoER2 raises the possibility that defective delivery of selenium to neurons contributes to the development of neurodegenerative conditions.

\section{References}

Beffert U, Weeber EJ, Durudas A, Qiu S, Masiulis I, Sweatt JD, Li WP, Adelmann G, Frotscher M, Hammer RE, Herz J (2005) Modulation of synaptic plasticity and memory by Reelin involves differential splicing of the lipoprotein receptor Apoer2. Neuron 47:567-579.

Beffert U, Durudas A, Weeber EJ, Stolt PC, Giehl KM, Sweatt JD, Hammer RE, Herz J (2006a) Functional dissection of Reelin signaling by sitedirected disruption of Disabled-1 adaptor binding to apolipoprotein $\mathrm{E}$ receptor 2: distinct roles in development and synaptic plasticity. J Neurosci 26:2041-2052.

Beffert U, Nematollah Farsian F, Masiulis I, Hammer RE, Yoon SO, Giehl KM, Herz J (2006b) ApoE receptor 2 controls neuronal survival in the adult brain. Curr Biol 16:2446-2452.

Burk RF (2006) Selenium (Se) and antioxidant mechanisms. Free Radical Res 40:S50.

Burk RF, Lane JM (1983) Modification of chemical toxicity by selenium deficiency. Fundam Appl Toxicol 3:218-221.

Burk RF, Hill KE (2005) Selenoprotein P: an extracellular protein with unique physical characteristics and a role in selenium homeostasis. Annu Rev Nutr 25:215-235.

Burk RF, Hill KE, Read R, Bellew T (1991) Response of rat selenoprotein P to selenium administration and fate of its selenium. Am J Physiol 261:E26-E30.

Burk RF, Hill KE, Awad JA, Morrow JD, Kato T, Cockell KA, Lyons PR (1995) Pathogenesis of diquat-induced liver necrosis in seleniumdeficient rats. Assessment of the roles of lipid peroxidation by measurement of $\mathrm{F}_{2}$ isoprostanes. Hepatology 21:561-569.

Burk RF, Hill KE, Motley AK, Austin LM, Norsworthy BK (2006) Deletion of selenoprotein $\mathrm{P}$ upregulates urinary selenium excretion and depresses whole-body selenium content. Biochim Biophys Acta 1760:1789-1793.

D'Arcangelo G, Homayouni R, Keshvara L, Rice DS, Sheldon M, Curran T (1999) Reelin is a ligand for lipoprotein receptors. Neuron 24:471-479.
Hartfuss E, Forster E, Bock HH, Hack MA, Leprince P, Luque JM, Herz J, Frotscher M, Gotz M (2003) Reelin signaling directly affects radial glia morphology and biochemical maturation. Development 130:4597-4609.

Herz J, Bock HH (2002) Lipoprotein receptors in the nervous system. Annu Rev Biochem 71:405-434.

Hill KE, Zhou J, McMahan WJ, Motley AK, Atkins JF, Gesteland RF, Burk RF (2003) Deletion of selenoprotein P alters distribution of selenium in the mouse. J Biol Chem 278:13640-13646.

Hill KE, Zhou J, McMahan WJ, Motley AK, Burk RF (2004) Neurological dysfunction occurs in mice with targeted deletion of selenoprotein $P$ gene. J Nutr 134:157-161.

Hill KE, Zhou J, Austin LM, Motley AK, Ham AJ, Olson GE, Atkins JF, Gesteland RF, Burk RF (2007) The selenium-rich C-terminal domain of mouse selenoprotein $\mathrm{P}$ is necessary for supply of selenium to brain and testis but not for maintenance of whole-body selenium. J Biol Chem 282:10972-10980.

Hondal RJ, Ma S, Caprioli RM, Hill KE, Burk RF (2001) Heparin-binding histidine and lysine residues of rat selenoprotein P. J Biol Chem 276:15823-15831.

Kawaguchi R, Yu J, Honda J, Hu J, Whitelegge J, Ping P, Wiita P, Bok D, Sun $\mathrm{H}$ (2007) A membrane receptor for retinol binding protein mediates cellular uptake of vitamin A. Science 315:820-825.

Kim DH, Iijima H, Goto K, Sakai J, Ishii H, Kim HJ, Suzuki H, Kondo H, Saeki S, Yamamoto T (1996) Human apolipoprotein E receptor 2. A novel lipoprotein receptor of the low density lipoprotein receptor family predominantly expressed in brain. J Biol Chem 271:8373-8380.

Koh TS, Benson TH (1983) Critical re-appraisal of fluorometric method for determination of selenium in biological materials. J Assoc Off Anal Chem 66:918-926.

Kryukov GV, Castellano S, Novoselov SV, Lobanov AV, Zehtab O, Guigo R, Gladyshev VN (2003) Characterization of mammalian selenoproteomes. Science 300:1439-1443.

Lawrence RA, Burk RF (1976) Glutathione peroxidase activity in seleniumdeficient rat liver. Biochem Biophys Res Commun 71:952-958.

Ma S, Caprioli RM, Hill KE, Burk RF (2003) Loss of selenium from selenoproteins: conversion of selenocysteine to dehydroalanine in vitro. J Am Soc Mass Spectrom 14:593-600.

Nakayama A, Hill KE, Austin LM, Motley AK, Burk RF (2007) All regions of mouse brain are dependent on selenoprotein $\mathrm{P}$ for maintenance of selenium. J Nutr 137:690-693.

Olson GE, Winfrey VP, Nagdas SK, Hill KE, Burk RF (2005) Selenoprotein $\mathrm{P}$ is required for mouse sperm development. Biol Reprod 73:201-211.

Olson GE, Winfrey VP, Nagdas SK, Hill KE, Burk RF (2007) Apolipoprotein E receptor-2 (ApoER2) mediates selenium uptake from selenoprotein $\mathrm{P}$ by the mouse testis. J Biol Chem 282:12290-12297.

Peters MM, Hill KE, Burk RF, Weeber EJ (2006) Altered hippocampus synaptic function in selenoprotein $\mathrm{P}$ deficient mice. Mol Neurodegener $1: 12$. See response for website

Saijoh K, Saito N, Lee MJ, Fujii M, Kobayashi T, Sumino K (1995) Molecu- 
lar cloning of cDNA encoding a bovine selenoprotein P-like protein containing 12 selenocysteines and a (His-Pro) rich domain insertion, and its regional expression. Mol Brain Res 30:301-311.

Schweizer U, Streckfuss F, Pelt P, Carlson BA, Hatfield DL, Köhrle J, Schomburg L (2005) Hepatically derived selenoprotein P is a key factor for kidney but not for brain selenium supply. Biochem J 386:221-226.

Sheehan TM, Gao M (1990) Simplified fluorometric assay of total selenium in plasma and urine. Clin Chem 36:2124-2126.

Thilakawardhana S, Everett DM, Murdock PR, Dingwall C, Owen JS (2005) Quantification of apolipoprotein E receptors in human brain-derived cell lines by real-time polymerase chain reaction. Neurobiol Aging 26:813-823.

Trommsdorff M, Gotthardt M, Hiesberger T, Shelton J, Stockinger W, Nimpf
J, Hammer RE, Richardson JA, Herz J (1999) Reeler/disabled-like disruption of neuronal migration in knock-out mice lacking the VLDL receptor and ApoE receptor 2. Cell 97:689-701.

Weeber EJ, Beffert U, Jones C, Christian JM, Forster E, Sweatt JD, Herz J (2002) Reelin and ApoE receptors cooperate to enhance hippocampal synaptic plasticity and learning. J Biol Chem 277:39944-39952.

Weisgraber KH, Mahley RW (1996) Human apolipoprotein E: the Alzheimer's disease connection. FASEB J 10:1485-1494.

Yang JG, Hill KE, Burk RF (1989) Dietary selenium intake controls rat plasma selenoprotein P concentration. J Nutr 119:1010-1012.

Yang X, Hill KE, Maguire MJ, Burk RF (2000) Synthesis and secretion of selenoprotein P by cultured rat astrocytes. Biochim Biophys Acta 1474: 390-396. 